\title{
Evaluation of biogenic and anthropogenic inputs of aliphatic hydrocarbons to Lake Taihu sediments using biomarkers
}

\author{
Wenchuan Qu $\cdot$ Bin Xue $\cdot$ Chenwei Su • \\ Sumin Wang
}

(C) Springer Science+Business Media B.V. 2007

\begin{abstract}
Surficial sediments from 13 sites throughout Lake Taihu, one of the largest urbanized freshwater lake systems in China, were analyzed for biomarkers (e.g., $n$-alkanes and hopanes) to track the origin of organic inputs (biogenic or anthropogenic), and, thus, to identify any 'hot spots' of hydrocarbon contamination. A distinct spatial distribution of aliphatic hydrocarbons in sediments was observed in Lake Taihu. At the northern tip of the lake (i.e., Meiliang and Wuli Bays), the highest mean aliphatic hydrocarbon concentration, with a significant contribution of an unresolved complex mixture (UCM), was found, indicating possible anthropogenic petroleum contamination (mainly from untreated and partially treated industrial and domestic sewage
\end{abstract}

Guest editors: B. Qin, Z. Liu \& K. Havens

Eutrophication of shallow lakes with special reference to Lake Taihu, China

W. Qu $(\bowtie) \cdot$ B. Xue · S. Wang

Key Laboratory of Lake Sediment \& Environment, Chinese Academy of Sciences, Nanjing 210008, China e-mail: wenchuan.qu@gmail.com

W. Qu

Australian Bureau of Statistics, Canberra, ACT 2615,

Australia

C. $\mathrm{Su}$

Research School of Biological Sciences, The

Australian National University, Canberra, ACT 0200,

Australia from Wuxi, Changzhou and other cities). This was supported by the n-alkane indices (e.g., small Carbon Preference Index and odd-to-even values) and a high degree of maturity of the hopane biomarkers. However, hydrocarbons from East Taihu were mainly biogenic, with the lowest mean concentrations, negligible or no contribution of UCM, abundance of vascular plant $\mathrm{C}_{23}-\mathrm{C}_{33} n$ alkanes with a high odd-to-even predominance, and the presence of biogenic hopanes (e.g., $17 \beta(\mathrm{H}), 21 \beta(\mathrm{H})$-hopanes and hopenes). In the other areas of the lake, however, the predominance of biogenic in combination with petrogenic hydrocarbons was indicated by the biomarkers.

Keywords Lake Taihu - Sediment . Biomarkers · Sources · Biogenic . Anthropogenic

\section{Introduction}

Aliphatic hydrocarbons (AHCs) are ubiquitous in aquatic sediments, and they derive from anthropogenic and natural sources (Zanardi et al., 1999). Potential long-term deleterious effects of hydrocarbon pollutants to organisms and human health, through trophic transfer, has driven intensive research to study hydrocarbon pollutant sourcing in aquatic environments using biomarkers and related indices (Albaiges \& Albrecht, 
1979; Qu et al., 1998; Commendatore et al., 2000; Barakat et al., 2002).

Lake Taihu is the third largest freshwater lake in China (Sun \& Huang, 1993; Qu et al., 1999; Qin et al., 2007). Pollution is one of the key environmental problems in Lake Taihu due to recent urbanization and industrial development, with associated increases in urban, industrial and rural pollution (TBA, 1998). For example, Meiliang Bay (at the northern tip) receives large amounts of untreated effluent from industries in Changzhou and Wujin, mainly through Zhihugang. Just beside Meiliang Bay, there is a small lagoon (area $\sim 10 \mathrm{~km}^{2}$ ) named Wuli Bay (Fig. 1), which receives millions of tons of domestic and industrial sewage each day, mainly via Liangxihe from Wuxi, a large city located $\sim 2 \mathrm{~km}$ northeast of Wuli Bay (Zou et al., 1996). The southeast part of Lake Taihu (East Taihu; area $131 \mathrm{~km}^{2}$ ) has macrophytes covering $\sim 97 \%$ of its total area and is referred to as a macrophyte-type basin.

In this article, surficial sediments from 13 sites in Lake Taihu were analyzed for biomarkers (e.g., $n$-alkanes and hopanes) to track origins of organic inputs (biogenic or anthropogenic) and identify 'hot spots' of hydrocarbon contamination.

\section{Materials and methods}

Sample collection

Surface sediments were collected using a metallic bucket grab sampler in February 2000 at stations shown in Fig. 1. Sites 1, 2 and 3 are located in Wuli Bay. Site 1 is close to the mouth of Liangxihe. Site 4 is located in west Meiliang Bay near the mouth of Zhihugang. Site 5 is located in central Meiliang Bay. Sites 11, 12, and 13 are located in East Taihu, and the other sites (6-10) are distributed in the West Basin. Sediment samples were returned to the laboratory and kept frozen until analyzed.

\section{Extraction and fractionation}

Sediment samples were dried in the air and sieved (100 mesh or $149 \mu \mathrm{m}$ ) to remove large particles of plant debris. About 50-100 g of sediment were extracted in a Soxhlet $\left(500 \mathrm{ml} ;(2: 1) \mathrm{CH}_{2} \mathrm{Cl}_{2} /\right.$ $\mathrm{MeOH}$ ) solution for $72 \mathrm{~h}$. Sulphur was removed by activated copper. Extracts were fractionated into aliphatic hydrocarbons and aromatic hydrocarbons on an activated silica/alumina column using hexane and benzene as eluents, respectively.
Fig. 1 Sampling sites in Lake Taihu

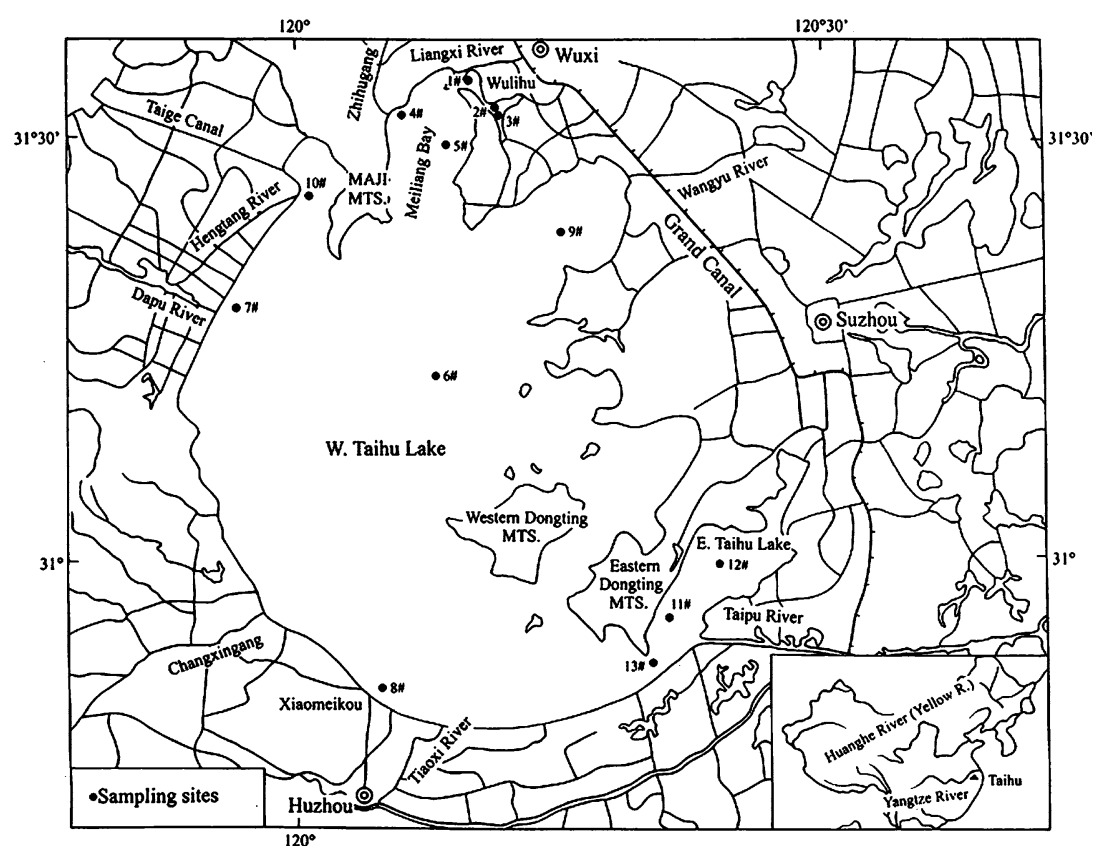


Gas chromatography and mass spectrometry

Aliphatic hydrocarbons were analyzed on a gas chromatography-mass spectrometry (GC-MS) instrument (HP5890 capillary GC-HP5989A quadrupole MS). Operating conditions were: a HP-5 fused silica capillary column $(30 \mathrm{~m} \times$ $0.25 \mathrm{~mm})$, high-purity $\mathrm{He}$ carrier gas $(>4.6)$; gradient temperature: $70 \rightarrow 300^{\circ} \mathrm{C}$, at $4^{\circ} \mathrm{C} / 60 \mathrm{~s}$; ion source temperature: $250^{\circ} \mathrm{C}$ and electron energy: $1.12 \times 10^{-17} \mathrm{~J}$ (Qu et al., 1998). Biomarkers were analyzed by monitoring $\mathrm{m} / \mathrm{z} 85$ (alkanes) and $\mathrm{m} / \mathrm{z}$ 191 (hopanes) using the GC/MS in Selected Ion Monitoring (SIM) mode (Qu et al., 1998).

Total organic carbon analysis

Total organic carbon (Org-C) was determined on dried sediments by $\mathrm{K}_{2} \mathrm{Cr}_{2} \mathrm{O}_{7}$ volumetry (Marr \& Cresser, 1983).

\section{Results and discussion}

Gas Chromatography—-total aliphatic hydrocarbon fraction

Concentration of total aliphatic hydrocarbons (AHCs, defined as the sum of resolved peaks plus the unresolved complex mixture, UCM) and organic carbon for 13 surface sediments in Lake Taihu are summarized in Table 1.

A distinct spatial distribution of aliphatic hydrocarbons in surface sediments was observed. High AHC concentrations ( $>300 \mu \mathrm{g} \mathrm{g}^{-1} \mathrm{dw}$ ) were found in sediments from Wuli Bay (Sites 1-3), with the highest concentration $\left(1,630 \mu \mathrm{g} \mathrm{g}^{-1} \mathrm{dw}\right)$ occurring at Site 1 (Table 1). This may be because Site 1 is close to the mouth of the Liangxihe, which carries large amounts of untreated domestic and industrial sewage from Wuxi and other small cities near Wuli Bay (Fig. 1). AHC concentration at Site 4 also was high $\left(342 \mu \mathrm{g} \mathrm{g}^{-1} \mathrm{dw}\right)$. This may be explained by its proximity to the mouth of Zhihugang, which carries about 20 million tons of industrial effluents annually from industrialized cities and towns (e.g., Changzhou and Wujin) (Sun \& Huang, 1993). AHC concentrations in sediments from other sites were lower $\left(<100 \mu \mathrm{g} \mathrm{g}^{-1} \mathrm{dw}\right)$, with the lowest occurring in East Taihu (36, 33 and $54 \mu \mathrm{g} \mathrm{g}^{-1} \mathrm{dw}$ for Sites 11, 12 and 13, respectively) (Table 1), which is likely due to the greater distance from major urban and industrial areas and, thus, anthropogenic hydrocarbon sources. The same spatial distribution pattern was found for other micropollutants, such as polycyclic aromatic hydrocarbons (PAHs) $(\mathrm{Qu}$ et al., 2002).

To reduce variability from organic matter dilution by inorganics and, thus, better evaluate sediment hydrocarbon pollution, AHC concentrations (in $\mu \mathrm{g} \mathrm{g}^{-1}$ ) were normalized to organic carbon content $(\mathrm{Org}-\mathrm{C} \%)$. The ratio of $\mathrm{AHC}$ concentration to Org- $\mathrm{C} \%$ has been used as a diagnostic tool, proposing that hydrocarbon (petroleum) pollution is present when the ratio is $>50$ (Boehm, 1984; Hong et al., 1995). In this study, Sites 1-4 showed the highest Org-C-normalized AHC concentrations (ranging from 144 to 426), indicating the presence of substantial hydrocarbon contamination at the northern tip of the lake. Sediments from East Taihu (Sites 11,12 and 13) had the lowest ratios (ranging from 14 to 52) and were considered unpolluted. AHCs in the remaining sediment samples (mainly from the West Basin) were intermediate relative to Org-C and appeared to be slightly contaminated

GC/MS SIM analysis of alkane biomarkers for AHC source tracing

To distinguish probable sources of AHCs (anthropogenic or biogenic) in surface sediments, different n-alkane evaluation parameters, such as UCM index, carbon preference index (CPI) and even-to-odd carbon number predominance (OEP) ratios, were analysed in addition to absolute concentrations.

UCM is a mixture of chromatographically unresolved components (e.g., many structurally complex isomers and homologues of branched and cyclic hydrocarbons) seen as a 'hump' in the chromatogram (Hostettler et al., 1989; Hong et al., 1995). UCM magnitude is related to the degree of anthropogenic (petroleum) contribution (Mazurek \& Simoneit, 1984; Commendatore et al., 2000). UCM is shown clearly in gas chromatograms of aliphatic hydrocarbons in heavily 
Table 1 Concentrations of total aliphatic hydrocarbons (AHCs), organic carbon (Org-C), alkane and hopane biomarker parameters for 13 sediment samples in Lake Taihu

\begin{tabular}{|c|c|c|c|c|c|c|c|c|c|c|c|}
\hline Locations & $\begin{array}{l}\text { Org-C } \\
(\%)\end{array}$ & $\begin{array}{l}\mathrm{AHC} \\
\mu \mathrm{g} \mathrm{g}^{-} \\
{ }^{1} \mathrm{dw}\end{array}$ & $\mathrm{UCM}^{\mathrm{a}}(\%)$ & $\begin{array}{l}\text { AHCl } \\
\text { Org-C }\end{array}$ & $\begin{array}{l}\text { Odd/ } \\
\text { Even } \\
\text { (OEP) }\end{array}$ & $\begin{array}{l}\mathrm{CPI}^{\mathrm{b}}{ }_{24-} \\
34\end{array}$ & $\begin{array}{l}\mathrm{o}_{30} \text {-hopenes/ } \\
\text { total hopanes }\end{array}$ & $\begin{array}{l}\mathrm{Tm} / \\
\mathrm{Ts}^{\mathrm{c}}\end{array}$ & $\begin{array}{l}\mathrm{C}_{30} \beta \alpha / \\
(\alpha \beta+\beta \alpha)\end{array}$ & $\begin{array}{l}\mathrm{C}_{30} \beta \beta / \\
\alpha \beta\end{array}$ & $\begin{array}{l}\mathrm{C}_{31} \mathrm{~S} / \\
(\mathrm{S}+\mathrm{R})\end{array}$ \\
\hline 1 & 3.83 & 1630 & 80 & 426 & 1.6 & 1.8 & 1.1 & 0.90 & 0.08 & 0.00 & 0.53 \\
\hline 2 & 2.05 & 337 & 60 & 164 & 1.9 & 2.4 & 4.9 & 0.91 & 0.10 & 0.00 & 0.54 \\
\hline 3 & 2.16 & 312 & 65 & 144 & 2.0 & 2.0 & 4.7 & 0.92 & 0.10 & 0.00 & 0.55 \\
\hline 4 & 1.86 & 342 & 60 & 184 & 1.6 & 2.1 & 1.6 & 0.80 & 0.06 & 0.00 & 0.58 \\
\hline 5 & 1.06 & 93 & 45 & 87 & 2.1 & 2.6 & 6.0 & 0.94 & 0.18 & 0.00 & 0.53 \\
\hline 6 & 0.87 & 66 & 15 & 76 & 2.3 & 3.7 & 6.9 & 1.50 & 0.18 & 0.00 & 0.48 \\
\hline 7 & 0.82 & 73 & 40 & 89 & 2.8 & 3.7 & 6.3 & 1.00 & 0.13 & 0.00 & 0.52 \\
\hline 8 & 0.81 & 74 & 35 & 91 & 2.1 & 2.8 & 5.1 & 1.00 & 0.11 & 0.00 & 0.53 \\
\hline 9 & 0.94 & 52 & 15 & 55 & 2.3 & 3.3 & 9.6 & 1.70 & 0.15 & 0.00 & 0.52 \\
\hline 10 & 0.81 & 112 & 45 & 138 & 2.5 & 3.8 & 9.7 & 1.00 & 0.11 & 0.00 & 0.50 \\
\hline 11 & 1.99 & 36 & 6 & 18 & 3.1 & 5.8 & 36.1 & 2.00 & 0.20 & 0.50 & 0.41 \\
\hline 12 & 2.31 & 33 & 8 & 14 & 3.4 & 8.0 & 13.1 & 3.28 & 0.19 & 0.12 & 0.46 \\
\hline 13 & 1.04 & 54 & 7 & 52 & 2.9 & 4.4 & 10.0 & 1.80 & 0.18 & 0.10 & 0.48 \\
\hline
\end{tabular}

${ }^{\mathrm{a}} \mathrm{UCM}=$ Unresolved complex mixture

b $\mathrm{CPI}_{24-34}=1 / 2\left(\left[\left(\mathrm{C}_{25}+\mathrm{C}_{27}+\mathrm{C}_{29}+\mathrm{C}_{31}+\mathrm{C}_{33}\right) /\left(\mathrm{C}_{24}+\mathrm{C}_{26}+\mathrm{C}_{28}+\mathrm{C}_{30}+\mathrm{C}_{32}\right)\right]+\left[\left(\mathrm{C}_{25}+\mathrm{C}_{27}+\mathrm{C}_{29}+\mathrm{C}_{31}+\mathrm{C}_{33}\right) /\left(\mathrm{C}_{26}+\mathrm{C}_{28}+\mathrm{C}_{30}+\mathrm{C}_{32}+\mathrm{C}_{34}\right)\right]\right)$

c $\mathrm{Tm} / \mathrm{Ts}=17 \alpha(\mathrm{H})-22,29,30$-trisnorneohopane $/ 18 \alpha(\mathrm{H})-22,29,30$-trisnorneohopane (Please refer to the text for more explanations)

AHC polluted sediments (e.g., Site 4, Fig. 2a). Table 1 suggests that UCM accounted for $>60 \%$ of total AHCs in sediments from Sites 1 to 4 , indicating possible petroleum contamination. In contrast, sediments from East Taihu (Sites 11, 12 and 13) showed negligible UCM contribution $(<10 \%)$ (Fig. 2b), indicating absence of petrogenic inputs. UCM in other samples contributed about $10-50 \%$ to total AHCs, suggesting predominance of biogenic in combination with petrogenic hydrocarbons.

The CPI and OEP indices also are used as diagnostic criteria of hydrocarbon sources (anthropogenic or biogenic) in sediments (Hostettler et al., 1989). In most plant waxes, oddchain alkanes are 8-10 times more abundant than even-chain $n$-alkanes. Thus, vascular plants and unpolluted sediments usually show high OEP and $\mathrm{CPI}_{24-34}$ values (ranging from 3 to 6). However, petrogenic hydrocarbons often show a wide distribution range of $n$-alkanes, and the even/odd ratio shows no predominance, with CPI values around 1 (Colombo et al., 1989). As expected, samples from Wuli and Meiliang Bays displayed low CPI (ranging from 1.8 at Site 1 to 2.6 at Site 5) and OEP (ranging from 1.6 at Site 1 to 2.1 at Site 5) ratios (Table 1, Fig. 2c), which evidenced the presence of (riverine) petroleum residues in surface sediments at the northern tip of the lake. Lower CPI and OEP values occurred in samples from the West Basin (Sites 6-10), which indicates decreased contribution of petrogenic hydrocarbons. Samples from East Taihu (Sites 11, 12 and 13) showed the highest CPI (5.8, 8 and 4.4, respectively) and OEP ratios (3.1, 3.4 and 2.9, respectively) (Table 1 , Fig. $2 d$ ), confirming that these sediments contain mainly contributions from biogenic sources (i.e., vascular plants).

GC/MS SIM analysis of hopane biomarkers for source tracing

Chromatograms of the hexane fraction (Fig. 2) also showed some hopane biomarker peaks. Therefore, GC/MS SIM analysis of hopanes (m/z 191) was conducted to provide more information on AHC sources and spatial patterns, since these biomarkers are more resistant to degradation than alkanes and isoprenoids and retain their composition and distribution during various processes (Barakat et al., 2002).

In the AHC polluted sediments (Sites 1-4), the thermodynamically stable $17 \alpha(\mathrm{H}), 21 \beta(\mathrm{H})$-hopane (that is, $\alpha \beta$-hopane) series were more 


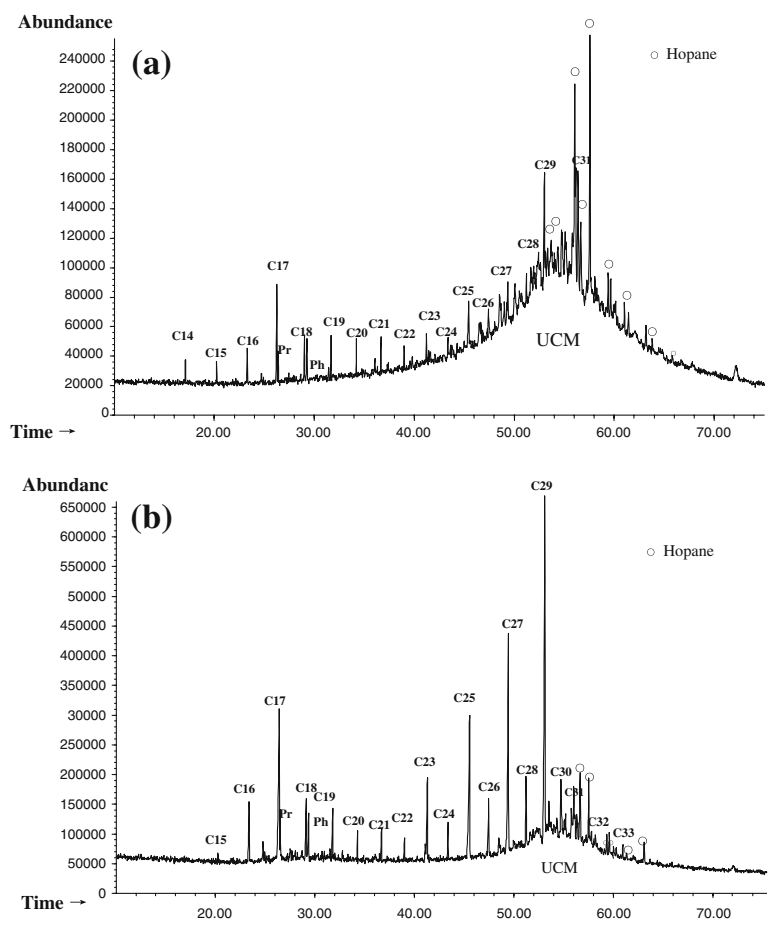

Fig. 2 Capillary column gas chromatograms of the hexane fraction of sediment samples from (a) Site 4 (representative of locations with mainly anthropogenic contributions) and (b) Site 13 (representative of locations with mainly

abundant than the less stable $\beta \alpha$-hopane series, natural biogenic $\beta \beta$-hopane series or mono-unsaturated hopanes (e.g., $\mathrm{C}_{30}$-hopenes) (Fig. 3a). These samples thus had a high degree of hopane biomarker maturity (e.g., lower ratios of $\mathrm{C}_{30} \beta \alpha$ l $(\alpha \beta+\beta \alpha), \quad \mathrm{C}_{30} \beta \beta / \alpha \beta \quad$ and $\% \quad \mathrm{C}_{30}$-hopenes) (Table 1), suggesting a contribution of petrogenic hydrocarbons. Further confirmation of petrogenic pollution was obtained from other geochemical maturity and source indicators. Mature sediments often have low $17 \alpha(\mathrm{H})-/ 18 \alpha(\mathrm{H})-22,29,30$-trisnorneohopane $(\mathrm{Tm} / \mathrm{Ts})$ ratios; extended $\alpha \beta$-hopanes (i.e., series with more than 30 carbon atoms) are resolved into two diastereomers (22S and $\mathrm{R}$ ) with high $\mathrm{S} /(\mathrm{S}+\mathrm{R})$ ratios near values for full maturity (equilibrium distribution) (e.g., approximately 0.6 for $\mathrm{C}_{31} \alpha \beta$-hopanes) (Hostettler et al., 1999). This is the case in samples from Sites 1 to 4 (Fig. 3a, Table 1 ).

However, hopane in East Taihu sediments were biogenic (e.g., $\beta \beta$-hopane series and monounsaturated hopanes) (Fig. 3b). These samples

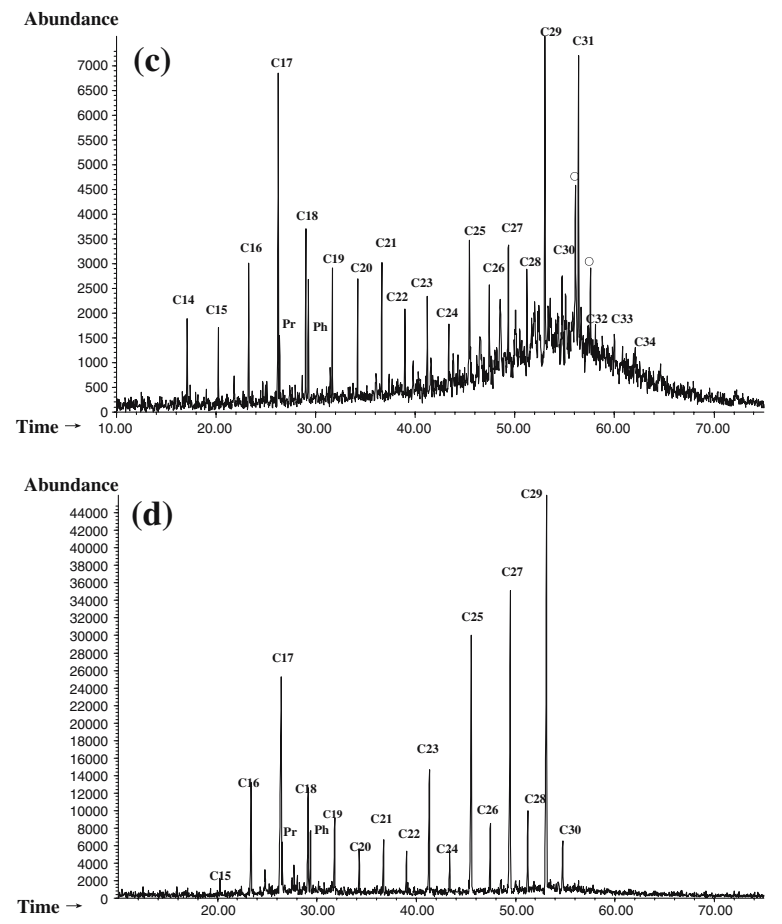

biogenic contributions); the $\mathrm{m} / \mathrm{z} 85$ ion chromatograms of sediment samples from (c) Site 4 and (d) Site 13 in Lake Taihu. Peaks labeled are the $n$-alkanes from $\mathrm{C}_{14}$ to $\mathrm{C}_{33}$ (14-33), pristine $(\mathrm{Pr})$, phytane $(\mathrm{Ph})$, and hopanes $(o)$

had the highest ratios of $\mathrm{C}_{30} \beta \alpha /(\alpha \beta+\beta \alpha)$ (ranging from 0.18 to 0.20$), \mathrm{C}_{30} \beta \beta / \alpha \beta$ (0.10 to 0.50$)$ and $\%$ $\mathrm{C}_{30}$-hopenes (10.0-36.1\%) (Table 1). Mass chromatograms (m/z 191) of these samples (e.g., Site 13, Fig. 3b) also showed extended $\alpha \beta$-hopane epimers and trisnorhopanes, Ts and Tm, indicating lower maturity (i.e., higher $\mathrm{Tm} / \mathrm{Ts}$ and lower $\mathrm{C}_{31} \mathrm{~S} /(\mathrm{S}+\mathrm{R})$ epimer ratios) (Table 1$)$. All these features are indications of low geochemical maturity and biogenic hydrocarbon sources. In addition, the rest of the samples, mainly from the Western Basin, showed a mixture of mature and immature constituents (Table 1), supporting the conclusion that these sediments contain both biogenic (i.e., vascular plants) and anthropogenic (i.e., petrogenic) sources.

\section{Conclusions}

In summary, Lake Taihu surficial sediments showed different levels and sources of aliphatic 


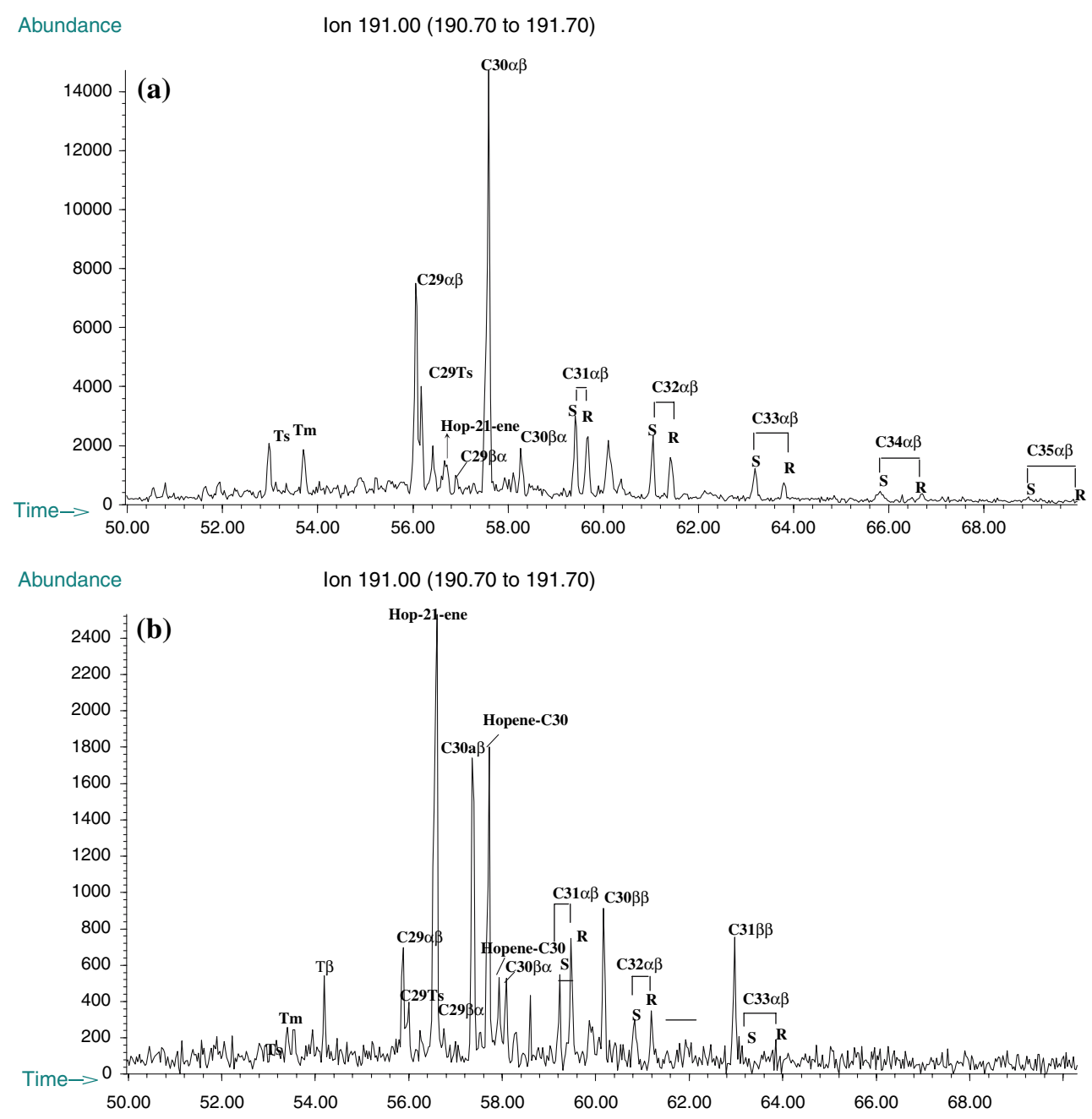

Fig. 3 Mass chromatograms of $\mathrm{m} / \mathrm{z} 191$ (hopanes) of surface sediment samples from (a) Site 4 and (b) Site 13 in Lake Taihu. Peaks identified are hopanes: Ts $=18 \alpha(\mathrm{H})$ 22,29,30-trisnorneohopane; $\quad \mathrm{Tm}=17 \alpha(\mathrm{H})-22,29,30$-trisnorneohopane; $\quad \mathrm{T}_{\beta}=17 \beta(\mathrm{H})-22,29,30$-trisnorneohopane; $\mathrm{C}_{29} \alpha \beta=17 \alpha(\mathrm{H}), \quad 21 \beta(\mathrm{H})$-30-norhopane; 29Ts $=18 \alpha(\mathrm{H})$ norneohopane; $\mathrm{C}_{29} \beta \alpha=17 \beta(\mathrm{H}), 21 \alpha(\mathrm{H})$-30-normoretane;

hydrocarbons, and biomarkers and related indices can provide information on anthropogenic contamination, especially related to petrogenic sources, as well as recent biogenic materials.

Near urban (e.g., Wuxi and Changzhou) and riverine (e.g., Zhihugang and Liangxihe) discharges, anthropogenic petrogenic AHC inputs were predominant. This was supported by: (1) high Org-C-normalized AHC concentrations; (2) significant contributions of UCM; (3) low
$\mathrm{C}_{30} \alpha \beta=17 \alpha(\mathrm{H}), 21 \beta(\mathrm{H})$-hopane; $\mathrm{C}_{30} \beta \alpha=17 \beta(\mathrm{H}), 21 \alpha(\mathrm{H})$ -

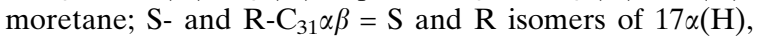
$21 \beta(\mathrm{H})$-homohopanes; $\quad \mathrm{C}_{30} \beta \beta=17 \beta(\mathrm{H}), \quad 21 \beta(\mathrm{H})$-hopane; S- and R- $\mathrm{C}_{32} \alpha \beta=\mathrm{S}$ and $\mathrm{R}$ isomers of $17 \alpha(\mathrm{H}), 21 \beta(\mathrm{H})$ bishomohopanes; $\mathrm{C}_{31} \beta \beta=17 \beta(\mathrm{H}), \quad 21 \beta(\mathrm{H})$-homohopane; S- and R- $\mathrm{C}_{33} \alpha \beta=\mathrm{S}$ and $\mathrm{R}$ isomers of $17 \alpha(\mathrm{H}), 21 \beta(\mathrm{H})-$ trishomohopanes

n-alkane CPI and OEP; and (4) the high degree of maturity of hopane biomarkers. On the contrary, East Taihu sediments exhibited: (1) the lowest level of AHCs; (2) negligible or no contributions of UCM; (3) high n-alkane CPI and OEP; and (4) low degree of maturity of hopane biomarkers. These features suggested that AHCs in these sediments have a dominant biogenic (vascular plants) origin. Biomarker parameters for Western Basin sediment samples, however, indicated the 
predominance of biogenic in combination with petrogenic hydrocarbons.

Information on sources and spatial variations of AHCs, together with other micropollutants, such as PAHs and heavy metals, may be useful in designing future strategies for protection and management of Lake Taihu.

Acknowledgements The authors thank Jiang Ji of Nanjing Institute of Geography \& Limnology, Chinese Academy of Sciences (CAS), for his help in the field. They are grateful to Minzhong Cui and Wanren Ding of Lanzhou Institute of Geology, CAS, for their assistance in the experimental analysis. Thanks are also due to the National Key Project for Basic Research on the Processes of Lake Eutrophication and the Mechanism of Cyanobacterial Blooming (No. 2002CB412301), Chinese Academy of Sciences; Knowledge Innovation Project "Environmental Effects Studies of Lake Sediment Dredging" (No. KZCX3-SW-348) and the 2005 Endeavour Australia Cheung Kong Awards for their financial aid.

\section{References}

Albaiges, J. \& P. Albrecht, 1979. Fingerprinting marine pollutant hydrocarbons by computerized gas chromatography-mass spectrometry. International Journal of Environmental Analytical Chemistry 6: 171-190.

Barakat, A. O., A. Mostafa, Y. Qian \& M. C. Kennicutt, 2002. Application of petroleum hydrocarbon chemical fingerprinting in oil spill investigation - Gulf of Suez, Egypt. Spill Science \& Technology Bulletin 7: 229239.

Boehm, P. D., 1984. Aspects of the saturated hydrocarbon geochemistry of recent sediments in the Georges Bank region. Organic Geochemistry 7: 11-23.

Colombo, J. C., E. Pelletier, C. Brochu \& M. Khalil, 1989. Determination of hydrocarbons sources using nAlkane and polyaromatic hydrocarbon distribution indexes. Case study: Rio de La Plata Estuary, Argentina. Environmental Science \& Technology 23: 888894.

Commendatore, M. G., J. L. Esteves \& J. C. Colombo, 2000. Hydrocarbons in coastal sediments of Patagonia, Argentina: levels and probable sources. Marine Pollution Bulletin 40(11): 989-998.
Hong, H., L. Xu, L. Zhang, J. C. Chen, Y. S. Wong \& T. S. M. Wan, 1995. Environmental fate and chemistry of organic pollutants in the sediment of Xiamen and Victoria Harbours. Marine Pollution Bulletin 31: 229236.

Hostettler, F. D., W. E. Pereira, K. A. Kvenvolden, A. Geen, S. N. Luoma, C. C. Fuller \& R. Anima, 1999. A record of hydrocarbon input to San Francisco Bay as traced by biomarker profiles in surface sediment and sediment cores. Marine Chemistry 64: 115-127.

Hostettler, F. D., J. B. Rapp, K. A. Kvenvolden \& S. N. Luoma, 1989. Organic markers as source discriminants and sediment transport indicators in south San Francisco Bay, California. Geochimica et Cosmochimica Acta 53: 1563-1576.

Marr, I. L. \& M. S. Cresser, 1983. Environmental Chemical Analysis. Blackie \& Son Ltd, London: 258.

Mazurek, M. A. \& B. R. T. Simoneit, 1984. Characterization of biogenic and petroleum-derived organic matter in aerosols over remote, rural and urban areas. Ann Arbor Science. Boston: 353-378.

Qin, B. Q, P. Z. Xu, Q. L. Wu, L. C. Luo \& Y. L. Zhang, 2007. Environmental issues of Lake Taihu, China. Hydrobiologia 581: 3-14.

Qu, W. C., M. Dickman, C. X. Fan, S. M. Wang, C. W. Su, L. Zhang \& H. X. Zou, 2002. Distribution, sources and potential toxicological significance of polycyclic aromatic hydrocarbons (PAHs) in Lake Taihu sediments, China. Hydrobiologia 485: 163-171.

Qu, W. C., M. Dickman, S. M. Wang \& R. J. Wu, 1999. Evidence for an aquatic origin of ketones found in Lake Taihu sediments. Hydrobiologia 397: 149-154.

Qu, W. C., M. Dickman, S. M. Wang, R. J. Wu, P. Z. Zhang, J. F. Chen \& H. J. He, 1998. Lake typology based on the use of sediment alkanes in the east and west basins of Lake Taihu, China. Hydrobiologia 364: 219-223.

Sun, S. C. \& Y. P. Huang, 1993. Taihu. The Ocean Press, Beijing: 271.

TBA, 1998. Eutrophication Assessment of Lake Taihu Report of China-Japan Co-operation Project in Lake Taihu. Taihu Basin Authority, Shanghai, 200 pp.

Zanardi, E., M. C. Bicego, L. B. Miranda \& R. R. Weber, 1999. Distribution and origin of hydrocarbons in water and sediment in Sao Sebastiao, SP, Brazil. Marine Pollution Bulletin 38(4): 261-267.

Zou, H. X., G. Y. Sheng, C. Sun \& O. Y. Xu, 1996. Distribution of organic contaminants in Lake Taihu. Water Research 30: 2003-2008. 